\title{
Editorial: Three-Dimensional Carbon Architectures for Energy Conversion and Storage
}

\author{
Tianyu Liu ${ }^{1 *}$, Teng Zhai ${ }^{2}$, Kaiyuan Shi ${ }^{3}$ and Hyun-Kyung Kim ${ }^{4}$ \\ ${ }^{1}$ Department of Chemistry, Virginia Polytechnic Institute and State University, Blacksburg, VA, United States, ${ }^{2}$ School of Materials \\ Science and Engineering, Nanjing University of Science and Technology, Nanjing, China, ${ }^{3}$ School of Materials Science and \\ Engineering, Sun Yat-sen University, Guangzhou, China, ${ }^{4}$ Department of Materials Science and Engineering, Kangwon National \\ University, Chuncheon, South Korea
}

Keywords: three-dimensional, carbon, energy conversion, energy storage, batteries, supercapacitors, electrocatalysis

\section{Editorial on the Research Topic:}

\section{Three-Dimensional Carbon Architectures for Energy Conversion and Storage}

\section{OPEN ACCESS}

Edited by:

Jun Yan,

Harbin Engineering University, China

Reviewed by:

Xu Xiao,

Drexel University, United States

*Correspondence:

Tianyu Liu

tliu23@vt.edu

Specialty section:

This article was submitted to Electrochemical Energy Conversion and Storage,

a section of the journal

Frontiers in Energy Research

Received: 29 September 2020

Accepted: 19 October 2020

Published: 12 November 2020

Citation:

Liu T, Zhai T, Shi K, Kim H-K (2020) Editorial: Three-Dimensional Carbon Architectures for Energy Conversion

and Storage.

Front. Energy Res. 8:611537. doi: 10.3389/fenrg.2020.611537
Meeting our expectation, this Research Topic has served as a global forum to report, communicate, and discuss the state-of-the-art of three-dimensional (3D) carbon materials in the context of energy conversion and storage. By the closing date in mid-September, 2020, the Research Topic has collected nine manuscripts contributed from 58 authors and gathered over 13000 views in total. These data unequivocally demonstrate the impact and popularity of $3 \mathrm{D}$ carbon materials in electrochemical energy conversion and storage.

The six research articles highlight the versatility of 3D carbon architectures in a plethora of applications associated with energy conversion and storage. Luo et al. demonstrated a 3D network consisting of helical carbon nanotubes and reduced graphene oxide nanosheets. This material functioned as sulfur hosts in Li-sulfur batteries. Nawwar et al. reported $3 \mathrm{D} \mathrm{Fe}_{3} \mathrm{O}_{4}$-decorated carbon nanotube assemblies for capacitive charge storage. Yang et al. anchored $\mathrm{Rh}$ nanoparticles on 3D graphene aerogels to synthesize methanol oxidation catalysts in direct methanol fuel cells. Wang et al. fabricated symmetric supercapacitors using 3D porous graphene nanosheets derived from chitosan. Guo et al. sandwiched fluorophosphate $\mathrm{NaVPO}_{4} \mathrm{~F}$ nanoparticles between amorphous carbon/reduced graphene oxide 3D hosts, which led to high-performance cathode materials for sodium-ion batteries. Liu et al. supported sulfurdeficient $\mathrm{MoS}_{2-\mathrm{x}}$ nanoflakes onto 3D macroporous carbon paper and made efficient oxygen-reduction catalysts to promote the electrochemical charge-storage performance of $\mathrm{Li}^{-} \mathrm{O}_{2}$ batteries.

Additionally, the Research Topic also includes two review articles. Galek et al. surveyed the 3D hierarchically porous carbon materials as electrodes in electrochemical capacitors. Feng et al. reviewed the $3 \mathrm{D}$, ordered porous carbon materials for applications in electrocatalysis, rechargeable batteries, and supercapacitors. Both reviews timely summarized the state-of-the-art development of $3 \mathrm{D}$ porous carbon materials in energy conversion and storage.

Last but not least, Liu commented on several overlooking issues about 3D porous carbon supercapacitor electrodes, as well as discussed potential solutions to guide future researchers in relevant research fields.

The successful conclusion of this Research Topic is impossible without the consistent support from the professional editorial team of Frontiers in Energy Research, our authors, reviewers, and readers. We, as the guest editors of this Research Topic, are grateful for the in-house editors. They have provided us step-by-step instructions on how to initiate, disseminate, promote, and maintain our Research Topic. We appreciate all the authors to choose our Research Topic to publish their high-quality research works, thorough reviews, and thoughtful comments. We thank all the 
reviewers for keeping high bars to ensure the scientific rigidity, data integrity, and presentation clarity of all the submitted manuscripts. We hope that readers of our Research Topic will find the collected articles informative, insightful, and inspiring.

\section{AUTHOR CONTRIBUTIONS}

TL drafted and polished the editorial. All other authors proofread and approved the submission of this editorial.
Conflict of Interest: The authors declare that this editorial is written without any commercial or financial relationships that could be construed as a potential conflict of interest.

Copyright $\odot 2020 \mathrm{Liu}$, Zhai, Shi and Kim. This is an open-access article distributed under the terms of the Creative Commons Attribution License (CC BY). The use, distribution or reproduction in other forums is permitted, provided the original author(s) and the copyright owner(s) are credited and that the original publication in this journal is cited, in accordance with accepted academic practice. No use, distribution or reproduction is permitted which does not comply with these terms. 